\title{
Early results of low-level laser application for masticatory muscle pain: a double-blind randomized clinical study
}

\author{
Erkan Sancakli*, Bilge Gökçen-Röhlıg, Ali Balık, Değer Öngül, Selin Kıpırdı and Haluk Keskın
}

\begin{abstract}
Background: To evaluate the effect of Low Level Laser (LLL) application at the points of greatest pain in patients with chronic masticatory muscle pain.

Methods: A total number of 30 (21 women, 9 men, with a mean age of 39.2) were selected after the diagnosis of MPDS according to the Research Diagnostic Criteria for Temporomandibular Disorder (RDC/TMD). The patients were randomly divided into three groups; laser group I $(n=10)$; patients received the $L L L$ at the point of greatest pain, laser group II $(n=10)$; patients received LLL at pre-established points in the effected muscles and placebo group $(n=10)$. LLL and placebo were applied three times per week, for a total of 12 sessions. Mandibular mobility was examined, masticator muscles tenderness were assessed and PPT values were obtained. Subjective pain levels were evaluated using VAS. The measurements performed before the treatment and after the completion of the therapy. Descriptive statistics (mean, standard deviation, and frequency) Student's $t$-test, Mann-Whitney U-test and paired-sample $t$-tests were used for analysis.
\end{abstract}

Results: In both laser groups, there was a statically significant reduction in PPT values of the muscles, number of muscles without any pain on palpation increased significantly, mandibular movements' ranges were improved. Laser group I demonstrated statistically better results than the Laser group II in all of the measured values. Plasebo group did not show any statistically difference in any of the measured values.

Conclusions: LLLT can be accepted as an alternative treatment modality in the management of masticatory muscle pain and direct irradiation seems to effect better.

Trial registration: Current Controlled Trials ISRCTN31085, Date of registration 28/08/20145.

Keywords: Masticatory muscle pain, Low-level laser, Direct irradiation

\section{Background}

Temporomandibular disorders (TMDs) are probably the most common cause of pain of non-dental origin in the maxillofacial area [1]. The category of TMDs embraces a number of clinical problems related to masticator muscles, temporomandibular joint (TMJ) and associated structures, or both [2]. Such disorders are characterised by pain, joint sounds, and restricted mandibular movement. The incidence of TMD ranges from 40 to $75 \%$ in general populations [3] and approximately $65 \%$ of affected patients experience associated pain [4]. This great number of

\footnotetext{
* Correspondence: esancak@istanbul.edu.tr

* Correspondence: esancak@istanbul.edu.tr 34390 Istanbul, Turkey
}

patients is treated using different modalities, depending on the aetiology of signs and symptoms. Conservative, rather than aggressive and irreversible, treatment is preferred to relieve symptoms, diminish pain, and re-establish function $[5,6]$. As the aetiology of TMD is multifactorial, available treatments are extensive and diverse, including the use of occlusal splints, low-level laser therapy (LLLT), and transcutaneous electrical nerve stimulation, among many others. Given that better therapeutic results (i.e. pain relief) are obtained with the combined use of modalities, several recent studies have examined the use of LLLT to reduce TMD pain and promote biostimulation effects [7-9].

LLLT, also known as 'soft laser therapy', has been investigated and used in the treatment of musculoskeletal pain 
syndromes for more than 3 decades. Numerous studies have demonstrated that LLLT effectively relieves pain and helps to re-establish normal function in patients with TMD [7-10]. Interest in this method is probably attributable to its ease of use and low cost, although it is time consuming. LLLT has been found to have analgesic, myorelaxant, tissue healing, and biostimulation effects [7-9]. The mechanisms of LLLT essentially rely on particular visible red and infrared light waves in photoreceptors within sub-cellular components, particularly the respiratory chain within mitochondrial membranes $[11,12]$. This light absorption causes activation of the respiratory chain and oxidation of the nicotinamide adenine dinucleotide hydrogen pool, which leads to a complex metabolic process culminating in the stimulation of normal cell function of the cell.

The body of literature on LLLT is large, but the results of randomised and non-randomised clinical studies (including those with double-blind designs) are controversial. The protocols used in clinical studies have varied in terms of power intensity and location of laser application. Although a 632.8-nm neon-helium laser [13]. and 660-nm [14], 780-nm [14, 15], 810-nm [16], 904-nm [17], and 830-904-nm [10] soft lasers have been used and reported to be effective, the most common wavelength in therapeutic use is probably 810-830 nm [18-21]. No consensus has been reached on the choice of laser application sites for the treatment of muscle pain. Some studies have employed laser application only at pre-established points in the affected muscles [13, 22] or acupuncture points [23], whereas few studies $[10,24,25]$ have targeted the point of greatest pain. Evidence for the best laser application site for the treatment of TMD of muscular origin is insufficient. Thus, the aim of this study was to investigate the efficacy of LLLT application at different sites in the treatment of TMD of muscular origin. We expected that direct application of LLLT at the point of greatest pain would reduce muscle pain to a greater degree than would application at pre-established points and placebo.

\section{Methods}

This study was performed at the Department of Prosthodontics, School of Dentistry, University of Istanbul, Turkey. Patients with orofacial pain who reported to the school's primary TMD referral centre were selected over a period of approximately 13 months (September 2010 - October 2011). Sample selection was based on standardised clinical examination using the following inclusion criteria: 1) diagnosis of myofascial pain according to the Research Diagnostic Criteria for Temporomandibular Disorder (RDC/TMD) [26], 2) age 18-60 years, and 3) natural posterior occlusion. Exclusion criteria were: 1) disc displacement with reduction or without reduction with or without limited opening, arthralgia, arthritis, or arthrosis; 2) general inflammatory connective tissue disease (e.g. rheumatoid arthritis); 3) psychiatric disorder; 4) tumour; 5) hearth disease or pacemaker; 7) pregnancy; 8) symptoms that could be referred to other orofacial region diseases (e.g. toothache, neuralgia, migraine); 9) treatment or medication use for headache or bruxism in the last 2 years; and 10) local skin infection over the masseter muscle. The Ethics Committee of the Istanbul University Faculty of Medicine approved the study protocol. All participants received a full explanation of the study and provided written informed consent.

\section{Study protocol}

This study was a double-blind randomised clinical trial (RCT). Participants were divided randomly into 3 ageand sex-matched groups: laser group I (LGI), laser group II (LGII) and the placebo group (PG). The randomizations of the patients were done with the help of a computer program. Patients were unaware of their group assignments. All participants underwent three treatment sessions per week for 1 month (total, 12 sessions). An experienced prosthodontist who was blinded to the applied treatment evaluated the patients twice: $30 \mathrm{~min}$ before the first laser application session and $30 \mathrm{~min}$ after the last laser application session. Evaluation consisted of 1) functional examination, 2) pressure pain threshold (PPT) measurement, and 3) subjective pain intensity measurement.

One week before the study began and during the course of the study, patients were asked not to take any analgesic or receive pain treatment. At the end of the study, patients in the PG received suitable treatment, such as an occlusal appliance or physical therapy.

\section{Laser exposure}

A continuous low-intensity semiconductor (Doris Diode Laser, CTL 1106 MX; Warsaw, Poland) was used for laser exposure. This device generates continuous radiation with regulated power. The single-probe laser device applies a laser diode generating infrared radiation of $820 \mathrm{~nm}$ wavelength. The beam diameter of the device is $6 \mathrm{~mm}$ and the probe has an angle of $45^{\circ}$. The energy intensity given to each muscle point was adjusted to $3 \mathrm{~J} / \mathrm{cm}^{2}$ by applying $300 \mathrm{~mW}$ output power for $10 \mathrm{~s}$.

In all groups, the laser was applied at a $2-\mathrm{mm}$ distance. In LGI, LLLT was applied precisely and continuously to the greatest points of pain in the related muscle (masseter and/ or temporalis). In LGII, LLLT was applied in the same manner to three predetermined points on the masseter muscle (superior $[\mathrm{MS}]$, middle $[\mathrm{MM}]$, and inferior [MI] points) and three points on the temporalis muscle (anterior [TA], middle, and posterior points). In the PG, the laser device was switched on, but not programmed. 


\section{Functional examination}

Functional examination was based on Kurkcu's official Turkish translation of the RDC/TMD [26]. The same prosthodontist examined all patients after calibration using the RDC/TMD as the gold standard.

Masticatory muscle tenderness was assessed bilaterally by palpation. Mobility of the mandible on opening, lateral excursions, and protrusion was measured with a plastic millimetre-scale ruler. Alterations in the opening pathway were also evaluated. Patients were asked to report any pain during muscle palpation and mandibular movements, and this information was recorded using a verbal scale: 0 , no pain; 1 , mild pain; 2 , moderate pain; and 3 , severe pain.

\section{Pressure pain threshold measurement}

After calibration, an experienced prosthodontist used a dial algometer (Pain Test ${ }^{\mathrm{Tm}}$ Model FPK; Wagner Instruments, Greenwich, CT, USA) to measure PPTs $\left(\mathrm{kg} / \mathrm{cm}^{2}\right)$ on the masticatory muscles. Compressions were performed using a $1-\mathrm{cm}^{2}$ rubber tip. After performing a few test measurements on each participant's lower arm, PPT values were obtained before and after treatment by applying pressure to the bilateral MS, MM, MI, and TA points. Patients were instructed to state immediately when the feeling of pressure became painful, at which time the pressure was stopped. Measurements were separated by 30 -s rest periods.

\section{Pain intensity measurement}

The participants were asked to evaluate their overall pain. Their subjective pain levels $(\mathrm{mm})$ were evaluated using a 100-mm visual analogue scale (VAS) before and after treatment.

\section{Statistical analysis}

Under the assumption of a difference of one standard deviation in the primary endpoint among groups, an alpha level of $5 \%$, and a power goal of $80 \%, 10$ patients per group were determined to be necessary. For all statistical tests, NCSS 2007 and PASS 2008 Statistical \& Power Analysis Software (NCSS, Kaysville, Utah, USA) were used. Descriptive statistics (mean, standard deviation, and frequency) were calculated for all variables. Quantitative data were compared using Student's $t$-test for normally distributed parameters and the Mann-Whitney $U$-test for non-normally distributed parameters. Within-group comparison of normally distributed parameters was performed using paired-sample $t$-tests. The results were analysed using $95 \%$ confidence intervals, with a significance level of $p<0.05$.

\section{Results}

Sixty-two of 814 examined patients with TMD of muscular origin fulfilled the inclusion criteria, and 33 of these patients agreed to participate in the study. Three enrolled patients did not attend appointments regularly and were excluded from the study. The study sample thus comprised 30 patients with TMD of muscular origin (21 women, 9 men; mean age, $39.2 \pm 2.8$ years) allocated to the three study groups ( $n=10$ per group). We identified no significant difference in age, sex, or pain duration among groups. Participants' demographic characteristics are shown in Table 1.

Participants in all groups reported the most severe pain in the masseter muscle. Laser exposure significantly reduced pain on palpation and (Table 2). Pain severity also decreased slightly in the PG (Table 2). It demonstrates the percentage of the pain intensity of the examined muscles before and after real laser exposure and placebo laser application in each group. The intensity of pain was reduced more in LGI than in LGII. PPTs of the examined muscles increased significantly in the LLLT groups, but not in the PG (Table 3). Although the difference between LGI and LGII was not statistically significant, LGI demonstrated slightly better results. Vertical movement, lateral excursions, and protrusion also improved significantly in the LLLT groups (Table 4). Pre- and post-treatment VAS scores differed significantly in the LLLT groups, but not in the PG (Table 5). No patient reported any adverse effect related to laser application during or after the treatment period.

\section{Discussion}

The present study demonstrated that the tested type of LLLT, applied bilaterally, was beneficial in the treatment of TMD of muscular origin. Patients who received LLLT

Table 1 Demographic data of the groups

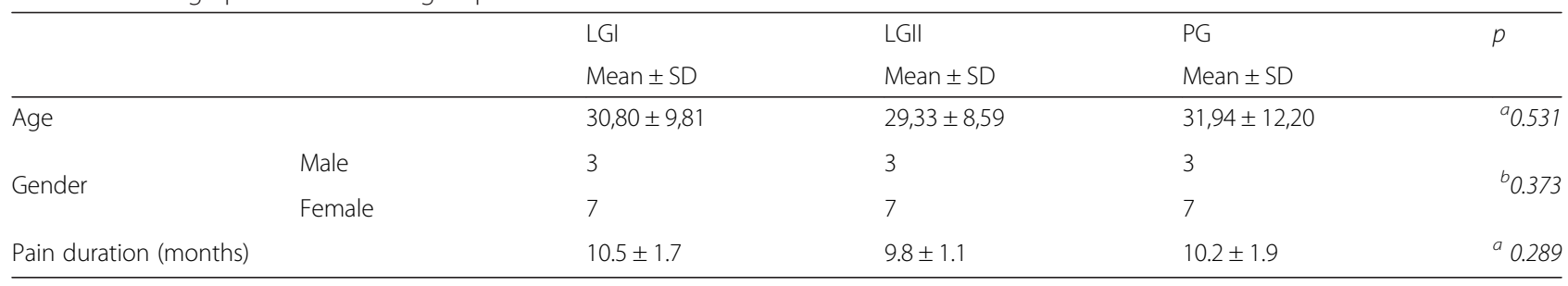

${ }^{a}$ Oneway ANOVA Test

${ }^{b}$ chi-square test 
Table 2 The results of muscle palpations

\begin{tabular}{|c|c|c|c|c|c|c|}
\hline & LGl & & LGII & & LGII & \\
\hline & $n(\%)$ & & $n(\%)$ & & $n(\%)$ & \\
\hline \multirow[t]{2}{*}{ TA } & Before treatment & 40 & Before treatment & 40 & Before treatment & \\
\hline & After treatment & 30 & After treatment & 30 & After treatment & \\
\hline \multirow[t]{2}{*}{ TM } & Before treatment & 40 & Before treatment & 40 & Before treatment & \\
\hline & After treatment & 30 & After treatment & 20 & After & \\
\hline \multirow[t]{2}{*}{ TP } & Before treatment & 10 & Before treatment & 40 & Before & \\
\hline & After $t$ & 10 & After treatment & 40 & After & \\
\hline \multirow[t]{2}{*}{ MS } & Before treatment & 80 & Before treatment & 80 & Before & \\
\hline & After treatment & 40 & After treatment & 60 & After treatment & \\
\hline \multirow[t]{2}{*}{ MM } & Before treatment & 90 & Before treatment & 80 & Before treatment & \\
\hline & After treatment & 60 & After treatment & 50 & After treatment & \\
\hline \multirow[t]{2}{*}{ Ml } & Befor & 80 & Before & 90 & nent & \\
\hline & After treatment & 40 & After treatment & 50 & After treatment & \\
\hline
\end{tabular}

$T A$ temporalis anterior, $T M$ temporalis middle, $T P$ temporalis posterior, MS masseter superior, $M M$ masseter middle, $M I$ masseter inferior

showed significant improvements in the tested parameters, whereas those in the PG did not. However, the study hypothesis that direct application of a low-level laser to the sites of most severe pain would produce better results than laser application at predetermined points was not supported. Direct application appeared to be slightly superior to traditional point irradiation, but differences were not significant.

Several previous clinical studies have investigated the effects of LLLT on TMD of myogenic origin using objective and subjective measures of PPTs, mandibular movements, and muscle pain on palpation [7-9]. The documented variation in these effects can be explained by many factors, including methodological differences among studies (e.g. use of placebo, double-blind design, sample characteristics) and LLLT parameters (e.g. application point, wavelength, power output, energy intensity, exposure duration). Furthermore, the effect of a low-level laser increases with the depth of penetration into musculoskeletal tissues. Wavelength and energy density play important roles in light penetration and absorption. In the current study, a light with $820 \mathrm{~nm}$ wavelength, $3 \mathrm{~J} / \mathrm{cm}^{2}$, and $300 \mathrm{~mW}$ output was used because these parameters have been reported to be effective for muscle disorders [10]. Gallium-arsenide lasers have been reported to penetrate to depths of $1-5 \mathrm{~cm}$ in soft tissue [27], which should be adequate to achieve a therapeutic effect in muscle disorders. The absence in the present study of a significant benefit of direct laser application to the points of greatest muscle pain, which we hypothesised would more effectively target affected tissue, may be due to the limited size of the treated muscle, which resulted in considerable similarity of such targeting to the treatment of predetermined points. In a muscle with larger area and greater thickness, such targeted application might achieve better results.

Pain was the chief complaint of patients in the current study. Pain levels were evaluated subjectively (with a VAS) at the beginning and end of the study. In clinical trials designed to investigate the efficacy of therapies aiming to resolve or reduce pain, the primary endpoint is reduction in pain intensity [28]. For chronic pain, most measures of treatment response involve patient-reported outcomes, as patients are the most important judges of whether changes are relevant [29-31]. The evaluation of pain is difficult because it is not controlled in clinical research; this complex procedure requires the assessment of biological, structural, functional, and emotional pain experiences. Recent chronic pain studies have recommended the evaluation of pain using subjectively reported primary measures $[28,29]$. However, clinical assessment should also involve an objective and quantitative evaluation of pain, such as PPT measurement, which enhances the quality of data and enables outcome standardisation and comparison. In the present study, objective functional measures based on the RDC/ TMD and PPT values were recorded with the aid of an algometer to accompany patient-reported pain intensity data. PPT values supported the VAS results.

Table 3 Comparison of PPT $\left(\mathrm{kg} / \mathrm{cm}^{2}\right)$ values. Each line demonstrates the statistical analysis of a muscle before and after laser exposure

\begin{tabular}{|c|c|c|c|c|c|c|c|c|c|}
\hline & \multicolumn{3}{|c|}{ Laser Group I } & \multicolumn{3}{|c|}{ Laser Group II } & \multicolumn{3}{|c|}{ Placebo Group } \\
\hline & $\overline{M\left(k g / \mathrm{cm}^{2}\right)}$ & SD & $p$ & $\overline{M\left(\mathrm{~kg} / \mathrm{cm}^{2}\right)}$ & SD & $p$ & $\overline{M\left(\mathrm{~kg} / \mathrm{cm}^{2}\right)}$ & SD & $p$ \\
\hline$\overline{T A}$ & 30.55 & 4.98 & $0.017532^{*}$ & 31.55 & 4.82 & $0.027532^{*}$ & 34.32 & 5.67 & $0.27757^{* *}$ \\
\hline$T M$ & 33.42 & 5.37 & $0.00922 *$ & 35.42 & 5.71 & $0.02022 *$ & 36.97 & 4.36 & $0.52936 * *$ \\
\hline$T P$ & 32.12 & 5.71 & $0.00574 *$ & 36.50 & 5.67 & $0.00274 *$ & 38.07 & 4.46 & $0.26742 * *$ \\
\hline MS & 22.75 & 5.52 & $0.00756 *$ & 23.11 & 5.86 & 0.00956 * & 25.50 & 6.00 & $0.55225 * *$ \\
\hline$M M$ & 20.87 & 4.87 & $0.00203 *$ & 19.45 & 4.44 & $0.00303 *$ & 23.60 & 4.72 & $0.94166 * *$ \\
\hline MI & 23.22 & 5.11 & $0.00032 *$ & 19.22 & 5.05 & $0.00062 *$ & 26.10 & 5.52 & $0.70732 * *$ \\
\hline SCM & 21.77 & 5.80 & $0.00031 *$ & 21.50 & 4.48 & $0.00061 *$ & 24.75 & 5.95 & $0.95113^{* *}$ \\
\hline
\end{tabular}

Student $t$ test was used

$M$ mean, SD Standard deviation, $95 \%$ confidence interval, ${ }^{*} p<0.05$ statistically significant, ${ }^{* *} p \geq .05$ statistically non-significant

TA temporalis anterior, TM temporalis middle, TP temporalis posterior, MS masseter superior, MM masseter middle, $M I$ masseter inferior, SCM sternocleidomasteideous 
Table 4 Mandibular movements. Each line demonstrates the statistical analysis of a mandibular movement after the assigned treatment and placebo application

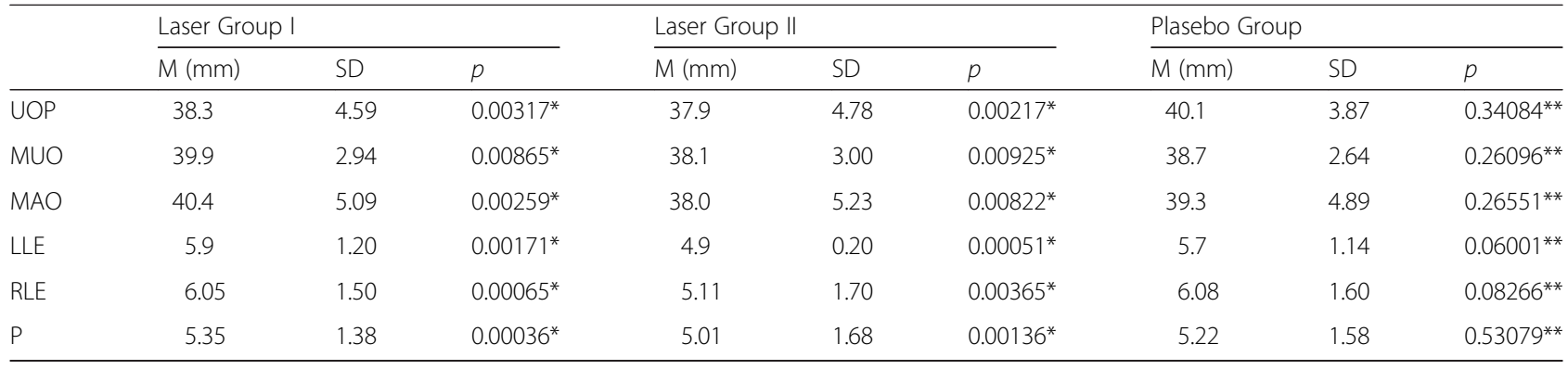

Student $t$ test was used

$M$ mean, SD Standard deviation, $95 \%$ confidence interval, ${ }^{*} p<0.05$ statistically significant, ${ }^{* *} p \geq 0.05$ statistically non-significant)

UOP unassisted opening without opening, MUO maximum unassisted opening, MAO maximum assisted opening, LLE left lateral excursion, RLE right lateral excursion, $P$ protrusion

In 2004, the World Association of Laser Therapy approved an agreement on the design of clinical studies employing LLLT; the use of a PG was established as a mandatory component [http://waltza.co.za/wpcontent/ uploads/2012/08/walt_standard_for_conduct_of_randomized_controlled_trials.pdf]. Accordingly, an age- and sex-matched PG was included in the present study. The PG showed slight, but not significant, improvement in all tested parameters. These improvements could be explained by many factors. The most likely explanation involves the positive reactions of patients to technologically advanced laser treatment. Furthermore, palpation, which was a treatment component for all study subjects (including those in the PG), can relieve pain [32].

The present study does have some limitations. The present study examined the effect of specific dose of LLLT on pain release and mandibular function and found out that active laser is superior to sham application. However the only the short-term effects were investigated. Additional research should be conducted in order to investigate the long-term effects of LLL in the treatment of TMD. Furthermore only one type of laser settings was used. Different light intensities might have produced different or better results. In order to be able to suggest a treatment protocol, a study population with greater sample size, followed-up for longer period and treated with different low-level laser parameter should be used.

Table 5 VAS scores according to groups

\begin{tabular}{lcc}
\hline & $\begin{array}{l}\text { Before Treatment } \\
\text { Mean } \pm \text { SD }\end{array}$ & $\begin{array}{l}\text { After Treatment } \\
\text { Mean } \pm \text { SD }\end{array}$ \\
\hline Laser Group I & $62.65 \pm 10.42$ & $31.46 \pm 7.14^{*}$ \\
Laser Group II & $58.38 \pm 7.25$ & $44.05 \pm 7.14^{*}$ \\
Plasebo Group & $53.31 \pm 8.79$ & $49.75 \pm 9.54^{* *}$ \\
\hline
\end{tabular}

${ }^{*}$ Mann-Whitney for differences before /after

${ }^{*} p<0.05$, statistically significant

${ }^{* *} p \geq 0.05$ statistically non-significant

\section{Conclusions}

Within the limitations of the present clinical trial, the tested type of LLLT $\left(820 \mathrm{~nm}, 3 \mathrm{~J} / \mathrm{cm}^{2}, 300 \mathrm{~mW}\right.$ output power) showed positive effects in managing pain caused by TMD and improving mandibular function due to its analgesic and myorelaxant effects. The localisation of laser application (at predetermined points $v s$. points of greatest pain), however, did not affect the results of LLLT. Further double-blind, randomised, placebo-controlled clinical research is needed to establish whether these findings have clinical relevance.

\section{Competing interests}

The authors declare that they have no competing interests.

\section{Authors' contributions}

ES: has the main responsibility for the study and manuscript preparation, he designed the study and controlled the data collection. BGR: designed the study and controlled the data collection together with Erkan Sancaklı and has the main responsibility for manuscript preparation. AB: carried out the treatments, participated in the design of the study and performed the statistical analysis. DÖ: performed the corrections of the manuscript during review process. SK collected the data and helped to draft the manuscript. HK department chair and participated in its design. All authors read and approved the final manuscript.

\section{Acknowledgement}

The authors wish to express gratitude to the enthusiastic and tolerant patients and students who took part in this study. The study was supported exclusively by the institutions of the authors.

Received: 5 March 2015 Accepted: 14 October 2015

Published online: 23 October 2015

\section{References}

1. Magnusson T, Egemark I, Carlsson GE. A longitudinal epidemiologic study of signs and symptoms of temporomandibular disorders from 15 to 35 years of age. J Orofac Pain. 2000;14:310-9.

2. Okeson JP. Orofacial pain: guidelines for assessment, diagnosis and management. Chigaco: Quintessence Publishing Co, Inc; 1996.

3. De Leeuw R. Orofacial Pain: Guidelines for assesement, diagnosis and management. 4th ed. Chicago: Quintessence; 2008.

4. Ozdemir-Karatas M, Peker K, Balık A, Uysal O, Tuncer EB. Identifying potential predictors of pain-related disability in Turkish patients with temporomandibular disorder pain. J Headache Pain. 2013;14:7.

5. Carlsson GE, Magnusson T. Management of Temporomandibular Disorders in the General Dental Practice. Chicago: Quintessence Publishing Co; 1999.

6. McNeill C. History and evolution of TMD concepts. Oral Surg. Oral Med Oral Pathol Oral Radiol Endod. 1997:83:51-60. 
7. Herpich CM, Amaral AP, Leal-Junior ECP, de Paiva J, Tosato CA, de Paula F, et al. Analysis of laser therapy and assessment methods in the rehabilitation of temporomandibular disorder: a systematic review of the literature. J Phys Ther Sci. 2015;27(1):295-301.

8. Sattayut S, Bradley P. A study of the influence of Low- Intensity Laser Therapy on Painful of the Temporomandibular Disorder Patients. Laser Ther. 2012;21(3):183-92.

9. Herranz-Aparicio J, Vazquez-Delgado E, Arnabt-Dominguez J, Espana-Tost A Gay-Escoda C. The use of low-level laser therapy in the treatment of temporomandibular disorders. Photomed Laser Surg. 2006;24:637-41.

10. Kato MT, Kogawa EM, Santos CN, Rodrigues PC. Tens and low-level laser therapy in the management of temporomandibular joint disorders. A review of the literature. Med Oral Patol Cir Bucal. 2013;18(4):e603-12.

11. Karu TI. Photobiology of low-power laser effects. Hith Phys. 1989;56:691-704.

12. Karu TI. Photobiology of low-power laser effects. London: Harwood Academic Publishers; 1989.

13. Emshoff R, Bösch R, Pümpel E,Schöning H, Strobl H. Low-level laser therapy for treatment of temporomandibular joint pain: a double blind and placebo-controlled trial. Oral Surg Oral Med Oral Pathol Oral Radil Endod.2008;105:452-6.

14. Venancio RA, Camparis CM, Lizarelli RFZ. Low intensity laser therapy in the treatment of temporomandibular disorders: a double-blind study. J Oral Rehabil. 2005;32:800-7.

15. Hakgüder A, Birtane M, Gürcan S, Kokino S. Efficacy of low level laser therapy in myofascial pain syndrome: an algometric and thermographic evaluation. Lasers Surg Med. 2003;33(5):339-43.

16. Tulberg M, Alstergen PJ, Ernberg MM. Effects of low-power laser exposure on masseter muscle pain and microcirculation. Pain. 2003;105(1-2):89-96.

17. Külekçioğlu S, Sivrioğlu K, Özcan O, Parlak M. Effectiveness of low-level laser therapy in temporomandibular disorder. Scan J Rheumatol. 2003;32:114-8.

18. Conti PC. Low level laser therapy in the treatment of temporomandibular disorders (TMD): a double-blind pilot study. J Craniomandib Pract. 1997:15:144-9.

19. Al P, Cavalcanti ET, Pinheiro TI, Alves MJ, Miranda ER, DeQuevedo AS, et al. low-level laser therapy is an important tool to treat disorders of the maxillofacial region. J Clin Laser Med Surg. 1998;16:223-6.

20. Simunovic Z. Low level laser therapy with trigger points technique: a clinical study on 243 patients. J Clin Laser Med Surg. 1996;14:163-7.

21. Özdemir F, Birtane M, Kokino S. The clinical efficacy of low-level laser therapy on pain and function in cervical osteoarthritis. Clin Rheumatol. 2001;20:181-4.

22. Cunha LA, Firoozmand LM, Silva AP, Esteves SA, Oliveira W. Efficacy of low-level laser therapy in the treatment of temporomandibular disorder. Int Dent J. 2008:58:213-7.

23. Leon IG, Almagro S, Garcia RC. Los trastornos temporomandibulares y la radiacion laser. Rev-Cubana Estomatol. 2007;44:1-8.

24. List T, Axelsso S. Management of TMD: evidence from systematic reviews and meta-analyses. J Oral Rehabil. 2010;37:430-51.

25. Venezian GC, Silva MA, Mazzetto RG, Mazzetto MO. Low level laser effects on pain to palpation and electromyographic activity in TMD patients: a double-blind, randomized, placebo-controlled study. Cranio. 2010;28:84-91.

26. Dworkin SF, LeResche L. Research diagnostic criteria for temporomandibular disorders: review, criteria, examinations and specifications, critique. J Craniomandib Disord Fac Oral Pain. 1992;6:301-55.

27. Gur A, Cosut A, Sarac AJ, Nas K, Karakoc M. Efficacy of low-level laser therapy and exercise on pain and functions in chronic low back pain. Lasers Surg Med. 2003;32:233-8.

28. Turk DC, Dworkin RH, Allen RR, Bellamy N, Brandenburg N, Carr DB, et al. Core outcome domains for chronic pain clinical trials: IMMPACT recommendations. Pain. 2003;106:337-45.

29. Dworkin RH, Turk DC, Wyrwich KW, Beaton D, Cleeland CS, Farrar JT, et al. Interpreting the clinical importance of treatment outcomes in chronic pain clinical trials: IMMPACT recommendations. J Pain. 2008:9(2):105-21.

30. Acquadro C, Berzon R, Dubois D, Leidy NK, Marquis P, Revicki D, et al. Incorporating the patient's perspective into drug development and communication: an ad hoc task force report of the Patient-Reported Outcomes (PRO) Harmonization Group meeting at the Food and Drug Administration, February 16, 2001. Value Health. 2003;6(5):522-31.
31. Turk DC, Dworkin RH, Burke LB, Gershon R, Rothman M, Scott J, et al. Developing patient-reported outcome measures for pain clinical trials: IMMPACT recommendations. Pain. 2006;125(3):208-15.

32. Simma I, Gleditsch JM, Simma L, Piehslinger E. Immediate effects of microsystem acupuncture in patients with oromyofacial pain and craniomandibular disorders (CMD): a double-blind, placebo-controlled trials. British Dental J. 2009;207:1-4

\section{Submit your next manuscript to BioMed Central and take full advantage of:}

- Convenient online submission

- Thorough peer review

- No space constraints or color figure charges

- Immediate publication on acceptance

- Inclusion in PubMed, CAS, Scopus and Google Scholar

- Research which is freely available for redistribution 